\title{
TRANSFERENCE
}

\author{
The shock of the new.
}

\section{BY JENNIFER CAMPBELL-HICKS}

$\mathrm{I}$ come to consciousness gently after transference, like rising from calm, deep water. I open my eyes. The recovery room is a washed-out blue with yellow undertones, as if I'm looking through a filter. A strong scent of lemon cleaner assaults my nose. After-effects of the procedure, I'm sure. I'm curled in a pillowed bed.

A middle-aged woman leans over me. She's wearing a lab coat, and her long blonde hair is tied back. Her scent is bitter and antiseptic. I decide she must be a doctor.

"Welcome back, Ms Bragin," she says. "How do you feel?"

I lift myself up and stretch, long and languid, from head to toes. How do I feel? Strong. Like I could run forever. It's much better than before I died, when my old body had wasted into weakness.

"Wonderful," I say.

The word doesn't come out as a word. It's a bark.

Startled, I jerk to my feet.

I look down. I have four paws, claws and golden fur. I look back. I have a tail that I have tucked between my legs.

Oh, no. No, no, no.

My will specifically stated that after my death, I wanted transference into the body of a god. I didn't specify which one. Greek, Norse, Egyptian, Hindu, whatever was available. Gods are ridiculously expensive. They take years to grow in the lab. But I had been filthy rich. What else would I do with the money, if not buy comfort in my next life?

Beautiful, pampered and adored. That's what I wanted.

Instead of god, I got dog.

“There's been a mistake!" I try to say, but my complaint emerges as a pathetic whine.

Who did this to me? Did my family misread my will? No, they would never have made such an error. Did my lawyer type it wrong? That's more likely. He always disliked me, and any typo of his might have been intentional. I bet he's laughing now.

$\rightarrow$ NATURE.COM

Follow Futures:

@ @NatureFutures

f go.nature.com $/ \mathrm{mtoodm}$
"It's all right, Ms Bragin," the doctor says. "It can take a few minutes to adjust to your new condition, but I promise you'll feel better soon." She scratches behind my ears, and oh, it's like heaven. My eyes drift shut. Despite myself, I lean into her hand. "Our canine clients have the highest satisfaction rate with their new life. Ninety-five per cent. Much better than cats."

impeccably, a queen of fashion and good taste. She smells like her favourite perfume and smiles when she sees me. I wag my tail. Tell the doctor, I think. Tell her they got it wrong. She cups my muzzle in both hands.

"Aunt Penny," she says. "Look at you. You're so beautiful, just like you always wanted. I know how much you loved golden retrievers. What lovely fur you have."

She strokes my back, from neck to tail. I shiver with delight, and my tail wags harder. I'm beautiful?

Wait. I don't want this.

Or do I?

My treacherous tongue is lolling. I pull it into my mouth and snap shut my muzzle.

Tell the doctor, I think, but my conviction is wavering.

"Let's get you out of here," Cindy says. "I'll take you to the park so you can test your new legs and chase some squirrels. When we get home, I'll have the cook make you a juicy steak."

My legs twitch, and my mouth waters. I have to admit, that sounds glorious. Maybe this isn't so bad. I could do worse. Like the doctor said, I could have ended up a cat. The park has plenty of squirrels in need of chasing, and I could breathe in fresh air instead of this sterile clinic smell. I could sniff the trees and add my own scent to introduce myself to the neighbourhood's canines.

Beautiful, pampered and adored. That's what I wanted. Who's more pampered and adored than a rich and beautiful dog?

I nuzzle at Cindy to show my agreement.

"Come on, Aunt Penny," she says.

I leap from the bed to follow her, my claws clicking on the linoleum floor. I can't wait to dig them into cool grass and dirt while I chase a squirrel up a tree.

Jennifer Campbell-Hicks is a writer, journalist, wife, mother and lifelong fan of science fiction and fantasy. Her fiction has appeared in Daily Science Fiction, Flash Fiction Online and Intergalactic Medicine Show. She blogs at jennifercampbellhicks. blogspot.com. 